\title{
A Public Health Issue: Dietary Supplements Promoted for Brain Health and Cognitive Performance
}

\author{
Cindy Crawford, BA, ${ }^{1,2}$ Courtney Boyd, MA, ${ }^{1,2}$ Bharathi Avula, PhD, ${ }^{3}$ Yan-Hong Wang, PhD, ${ }^{3}$ \\ Ikhlas A. Khan, $\mathrm{PhD}^{3,4}$ and Patricia A. Deuster, $\mathrm{PhD}, \mathrm{MPH}^{1}$
}

\section{Abstract}

Background: Dietary supplements targeting brain health have quickly emerged in the marketplace as cognitive performance becomes an important public health issue. While manufacturers are required to report the exact ingredients and formulations listed on the Supplement Facts labels of products, many reports have indicated such labels are not always truthful, and the content of some products is inconsistent with the ingredients listed on the Supplement Facts label.

Objectives: To identify dietary supplement products and ingredients marketed for brain health and cognitive performance and perform analyses of select products to verify whether purported claims are truthful and product labels accurate.

Design: A scoping review was performed to identify products and ingredients. Products were selected for content analysis, investigated for scientific-sounding claims made, and assessed using an educational tool for potential red flags when reading Supplement Facts labels.

Results: Twelve products were selected from the 650 products being marketed for brain health and queried about by Service Members. Eight (67\%) had at least one ingredient listed on the Supplement Facts label not detected through analysis. Compounds not reported on the label were detected in 10 (83\%) products. Scientificsounding claims made are not supported by science and red flags are presented.

Conclusions: There are dietary supplements targeting brain health being marketed to consumers that should be considered adulterated and misbranded. Advertisements and product labels may be deceiving and could put the public at risk. Education is required so that the public can recognize red flags while the U.S. Food and Drug Administration works to "modernize" the current regulations for dietary supplements.

Keywords: adulterated, cognition, dietary ingredients, dietary supplements, nutrition education

\section{Introduction}

D IETARY SUPPLEMENTS TARGETING brain health have quickly emerged in the marketplace as cognitive performance becomes an important public health issue. Products with promises of improved memory and focus to enhanced cognitive performance and energy, are widely available in stores on military bases, large and small retail stores, and across the Internet. In June 2019, the Global Counsel on Brain Health published a report-“"The Real Deal on Brain

\footnotetext{
${ }^{1}$ Consortium for Health and Military Performance, Department of Military and Emergency Medicine, F. Edward Hébert School of Medicine, Uniformed Services University, Bethesda, MD.

${ }^{2}$ Henry M. Jackson Foundation for the Advancement of Military Medicine, Bethesda, MD.

${ }^{3}$ National Center for Natural Products Research, School of Pharmacy, University of Mississippi, University, MS.

${ }^{4}$ Division of Pharmacognosy, Department of BioMolecular Sciences, School of Pharmacy, University of Mississippi, University, MS.

(C) Cindy Crawford, et al. 2020; Published by Mary Ann Liebert, Inc. This Open Access article is distributed under the terms of the Creative Commons Attribution Noncommercial License (http:/ /creativecommons.org/licenses/by-nc/4.0/) which permits any noncommercial use, distribution, and reproduction in any medium, provided the original author(s) and the source are cited.
} 
Health Supplements" - and cited growth statistics from the U.S. Government Accountability Office surrounding the brain health supplement market, specifically in terms of memory supplements:

"In the United States their sales nearly doubled in value from 2006 to 2015 , increasing to $\$ 643$ million in 2015 . According to an industry forecast report, the brain-health supplements generated $\$ 3$ billion in sales globally in 2016 , and that figure is projected to reach $\$ 5.8$ billion by 2023 .",

This market targets several populations: the aging concerned with or experiencing cognitive decline; healthy adults seeking to improve performance or prevent a decline; and elite performers such as Service Members (SM) seeking to optimize their cognitive performance. SM are a unique population commonly targeted by this market with claims to enhance power, focus, and energy.

Approximately $55 \%-76 \%$ of SM and $75 \%$ of the U.S. adult population use dietary supplements, often based on lay advice and a mixture of information from peers, friends, families, and/or other reliable or unreliable sources. ${ }^{2}$ Approximately $22 \%$ of users report one or more adverse events from taking dietary supplements. ${ }^{3}$ The majority of surveys conducted within the military concerning dietary supplement prevalence report on general use and categorize the types of supplements typically as vitamins, minerals, herbal products, and/or as body-building, energy, performance, or weight loss. ${ }^{3,4}$ The most compelling claims, the actual ingredients, and/or specific products frequently sought out and used are less known.

According to the 25-year-old Dietary Supplement Health and Education Act of 1994 (DSHEA), manufacturers and distributors of dietary supplements and dietary ingredients are responsible for evaluating the safety and ensuring the accuracy in labeling of their products before marketing to the public. The U.S. Food and Drug Administration (FDA) is responsible for taking action against any adulterated or misbranded dietary supplement product only after it reaches the market. For this reason and unlike prescription drugs, supplements are usually not necessarily tested or evaluated for safety or effectiveness. 5,6

In February 2019, the FDA commissioner released a statement to address the overall exponential growth and popularity in the dietary supplement market; new steps are being proposed for requirements around the dietary supplement manufacturer and labeling in the hopes of "modernizing" and improving its oversight. The FDA has issued many warning letters and advisory letters online directed at dietary supplement companies illegally selling products, which are considered unapproved new drugs and/or misbranded drugs that claim to prevent, treat, or cure Alzheimer's disease. ${ }^{7}$ In fact, the FDA report states:

\footnotetext{
"These products, which are often sold on websites and social media platforms, have not been reviewed by the FDA and are not proven safe and effective to treat the diseases and health conditions they claim to treat. These products may be ineffective, unsafe and could prevent a person from seeking an appropriate diagnosis and treatment.",
}

Whereas dietary supplements might provide benefits in certain cases, it is imperative that manufacturers provide sound evidence to support their claims before production. Endangering consumers by advertising products that could be harmful and deceiving consumers into spending money on products that are simply ineffective are not consistent with current regulations. Manufacturers are required to report the exact ingredients and formulations listed on the Supplement Facts labels of products. Unfortunately many reports have indicated such labels are not always truthful and the content of some products is inconsistent with the ingredients listed on the Supplement Facts label. ${ }^{5,6,8-13}$

With an ever-growing dietary supplement market focused on brain health and cognitive performance, SM as well as the public at large, must be equipped with trusted educational tools so that they can make appropriate and safe supplement purchasing decisions. The purpose of this project was to (1) identify dietary supplement products marketed for brain health and cognitive performance and determine the most prevalent ingredients contained in those products, and (2) perform qualitative analyses of select products that SM inquired about, their purported claims, and verify whether the ingredients claimed on the Supplement Facts labels were consistent with what they actually contain.

The goal of this effort is to begin educating the public and raising consumer awareness of what to consider when purchasing or recommending use of these products. In a separate effort, the authors are performing a comprehensive systematic review across the ingredients identified as contained in these products to generate evidence-based recommendations concerning the safety and effectiveness of select ingredients, and where possible, combinations of ingredients among populations most closely relevant to the elite warfighters.

\section{Methods}

\section{Identification of dietary supplement products and ingredients}

A scoping review was performed to identify dietary supplement products marketed for brain health and cognitive performance in otherwise healthy adults, and the most prevalent dietary ingredients contained in those products. Natural Medicines, the Dietary Supplement Label Database, and popular websites (e.g., GNC, Amazon.com), where military personnel may purchase products, were searched by using keyword terms such as "brain" and "cognitive" to identify relevant products. All ingredients within the identified products were recorded; ingredients repeatedly contained in at least 10 or more products across each of the searches were considered "frequently used" ingredients.

A total of 72 "frequently used" ingredients were identified across 650 unique products marketed for brain health/cognitive performance through the scoping review. An umbrella review and evidence mapping exercise were performed to diagram the extent of the systematic review and meta-analyses that have been published as well as document the eligibility of those publications in terms of the populations studied, interventions included, and outcomes assessed (Supplementary Data S1).

Forty-three percent (31/72) of the ingredients have been assessed through some type of systematic review methods across various populations, to include heterogeneous dose/ administration(s) for ingredients, and various brain health and cognitive performance-related outcomes (Supplementary Data S1). This exercise was performed to help inform decisions regarding the focus of the comprehensive systematic review, where gaps currently exist, as well as the specific and most meaningful research questions to target the populations the authors wish to serve (evidence forthcoming in a separate article). 
Next, questions submitted to the Operation Supplement Safety (OPSS.org) website concerning dietary supplement products or ingredients marketed for brain health/cognitive performance and their ingredients were reviewed (January 2018 to February 2019). OPSS.org is the Department of Defense resource for SM offering evidence-based information on dietary supplements and ingredients. An Ask the Expert feature is available where SM can ask specific questions about dietary supplements.

Of the 559 queries submitted, 50 questions concerned a dietary supplement marketed for cognitive enhancement and included "frequently used" ingredients from the scoping activity reported above; six duplicate queries were removed, resulting in a total of 44 products queried. An examination of the manufacturer websites for these remaining 44 products revealed that many were also being marketed as fat burners, muscle enhancement, testosterone boosters, and weight loss products. Twelve products reporting claims solely for brain health and cognitive enhancement were selected for analysis. It is likely that these products target this elite population with such claims as enhancing power, focus, and energy, and for which SM are often exposed (Supplementary Data S2: flow chart and search strategies).

These 12 products represented $\sim 2 \%$ of the 650 products and $70 \%$ of the 72 frequently used ingredients found through the scoping review. One bottle of each product was purchased over the Internet and sent to the National Center for Natural Products Research at the University of Mississippi to perform quality assessment and whether they included the ingredients listed on the Supplement Facts labels (Supplementary Data S3: instrumental and analytic conditions).

A qualitative analysis was also performed using the Operation Supplement Safety (OPSS.org) "scorecard" criteria to "quickly" screen the product label for potential safety. ${ }^{14}$ This scorecard is being used as an educational tool within the Department of Defense to teach SM and providers how to read dietary supplement product labels and identify potential red flags when considering products for purchase. ${ }^{15}$ Finally, product manufacturer websites were examined to document claims made for the product being advertised, any scientific-sounding claims, whether clinical research citations were presented to support claims, and if studies are peer-reviewed and published; and if there are any studies, who sponsored the work and whether they are on specific products or merely ingredients contained in products.

\section{Results}

The 12 products chosen for analysis were formulated as combinations of vitamins, minerals, amino acids, and herbal ingredients. Based on the Supplement Facts labels, vitamins consisted of vitamin $\mathrm{A}, \mathrm{B}, \mathrm{C}, \mathrm{D}$, and $\mathrm{E}$ with $\mathrm{B} 6$ and $\mathrm{B} 12$ being the most frequently reported in over half of the 12 products. Minerals such as calcium, magnesium, potassium, selenium, and zinc are noted on $\sim 25 \%$ of product labels. Frequently listed amino acids consisted of various forms of tyrosine, carnitine and its derivatives, glutamine, and theanine. Commonly reported herbal ingredients were Bacopa leaf (9/12) and Huperzine A (10/ 12) extracts. Other common ingredients are phosphatidylserine (8/12), vinpocetine (5/12), and coffee extracts (5/12).

All ingredients identified are detailed in Supplementary Data S1. The systematic review evidence that currently exists across these ingredients with outcomes related to cognitive performance and brain health is derived from healthy adults, elderly, otherwise healthy, cognitively impaired, or those experiencing Alzheimer's disease or dementia. The majority of this evidence is drawn from the elderly and impaired populations and most reviews reported insufficient evidence to recommend the combinations of vitamins, minerals, and/or various plant-based ingredients for cognitive protection. Less work has been conducted in elderly, otherwise healthy populations, and even fewer in healthy adults. Even less work has been conducted to document potential improvements in the performance of elite populations. ${ }^{16-22}$

\section{Qualitative analysis of products}

Of the 12 products analyzed, $8(67 \%)$ had at least 1 ingredient listed on the Supplement Facts label not detected through the analysis. In addition, $10(83 \%)$ products analyzed detected ingredients not reported on the Supplement Facts label (Table 1). Many of these ingredients not listed but detected are considered amino acids (phenylalanine or its derivatives were detected in six products, and carnitine and its derivatives were detected in three products), and others were acids used as flavoring agents or preservatives (e.g., citric acid, homocitric acid, and succinic acid). The majority of these ingredients detected are "naturally occurring compounds found in plants," however, it is unclear how much of these ingredients were added or whether they came from any plant extracts or sources not reported on the label.

Some ingredients that raise concern are adenosine or its derivatives, which were found in three products, and do not appear to be included in the FDA New Dietary Ingredient Notification database. It is unclear whether this is a drug or a natural ingredient. Ingredients such as sulbutiamine contained in one product and vinpocetine in five products appeared on product labels and were detected in analyses are considered mild stimulants. Sulbutiamine, now appearing on the FDA Advisory List, is a synthetic derivative of thiamine and has been used by athletes to enhance performance ${ }^{23}$; and vinpocetine is an ingredient that the FDA has recently issued a warning to consumers stating that it could cause "a miscarriage or harm fetal development." ${ }^{24}$ In some countries, this ingredient is a prescription drug. Caffeine was also detected in one product that explicitly highlighted "DECAFFEINATED" on the label. In addition, regardless if these ingredients are generally recognized as safe and allowed in dietary supplements, there is cause for concern as to how they may interact with other ingredients in the product, the amount contained in the product, and whether various formulations may alter the safety profiles.

\section{OPSS scorecard}

The OPSS scorecard is an educational tool and resource to help consumers within the Department of Defense community make informed decisions on dietary supplements. It contains seven criteria to quickly assess the relative safety potential of a dietary supplement according to the product label using a "go/no-go" overall rating. These are detailed below according to the 12 select products for analysis. A product that receives a "yes (1)" response to the questions below (Table 2) on four or more criteria is considered improved relative safety 
Table 1. Qualitative Analysis of 12 Select Brain Health/Cognitive Performance Dietary Supplements Based on Label Claim Verification Analysis

\begin{tabular}{|c|c|c|c|}
\hline Code no. & $\begin{array}{l}\text { Total no. of claimed } \\
\text { ingredients on label }\end{array}$ & $\begin{array}{l}\text { No. of claimed } \\
\text { ingredients not detected (\%) }\end{array}$ & Components detected but not on label \\
\hline NCNPR394PR & 24 & $6(25)$ & Phenylalanine $^{\mathrm{a}}$ \\
\hline NCNPR395PR & 7 & $1(14)$ & $\begin{array}{l}\text { Butyryl carnitine/isobutyryl- } L \text {-carnitine } \\
\text { Carnitine }^{\mathrm{a}} \\
\text { Chlorogenic acid }^{\mathrm{b}} \\
\text { Dicaffeoylquinic acids }\end{array}$ \\
\hline NCNPR408PR & 11 & $1(9)$ & $\begin{array}{l}\text { Homocitric acid/homoisocitric } \text { acid }^{\mathrm{c}} \\
\text { Phenylalanine }^{\mathrm{a}} \\
\text { Kaempferol or luteolin }^{\mathrm{d}}\end{array}$ \\
\hline NCNPR398PR & 13 & $3(23)$ & $\begin{array}{l}\text { Adenosine derivative } \\
5^{\prime}-\text { Methylthioadenosine } \\
\text { Adenosine }^{\mathrm{e}} \\
\text { Phenylalanine }^{\mathrm{a}}\end{array}$ \\
\hline NCNPR397PR & 15 & 0 & $\begin{array}{l}\text { Homocitric acid/homoisocitric } \text { acid }^{\mathrm{c}} \\
\text { Maltol/isomaltol }^{\mathrm{f}}\end{array}$ \\
\hline NCNPR393PR & 21 & $3(14)$ & $\begin{array}{l}\text { Phenylalanine }^{\mathrm{a}} \\
\text { Tartaric acid }^{\mathrm{c}} \\
\text { Succinic acid } \\
\text { Malic acid } \\
\text { Citric acid } \\
\text { Methyl nicotinate }\end{array}$ \\
\hline NCNPR412PR & 6 & 0 & $\begin{array}{l}\text { Caffeine } \\
\text { Citric } \text { acid }^{\mathrm{g}}\end{array}$ \\
\hline NCNPR392PR & 9 & 0 & - \\
\hline NCNPR399PR & 10 & 0 & - \\
\hline NCNPR406PR & 20 & $6(30)$ & $\begin{array}{l}\text { Leu-Gly/isoleucine-glycine }{ }^{\mathrm{a}} \\
\text { Propionylcarnitine }^{\mathrm{a}} \\
\text { Butyrylcarnitine }^{\mathrm{a}} \\
N \text {-Acetyl- } L \text {-phenylalanine } \\
N \text {-Lactoyl-phenylalanine/adenosine derivative }\end{array}$ \\
\hline NCNPR396PR & 7 & $1(14)$ & $\begin{array}{l}\text { Butyrylcarnitine/isobutyryl- } L \text {-carnitine } \\
\text { Chlorogenic acid }^{\mathrm{a}} \\
\text { Dicaffeoylquinic acids }\end{array}$ \\
\hline NCNPR469PR & 8 & $1(13)$ & $\begin{array}{l}N \text {-Acetyl- } L \text {-phenylalanine }{ }^{\mathrm{a}} \\
\text { Adenosine derivative } \mathrm{e}^{\mathrm{e}} \\
\text { Adenosine }^{\mathrm{e}}\end{array}$ \\
\hline
\end{tabular}

The total number of claimed ingredients column is the number of claimed ingredients for which the analysis was able to look for in the analysis, which is not always the same number as those ingredients on the label. For example, phosphatidylserine and fat soluble vitamins cannot be detected using this analysis and therefore are not in the number reported above. As noted in the text, some of these ingredients detected are "naturally occurring compounds found in plants," however, it is unclear how much of these ingredients were added or whether they came from any plant extract not reported on the label.

${ }^{a}$ Considered or derived from an amino acid.

${ }^{\mathrm{b}}$ Naturally occurring polyphenolic compound found in plants such as Coffea spp.

${ }^{\mathrm{c}}$ Acid typically used as flavoring agent or preservative.

${ }^{\mathrm{d}}$ Natural flavonol, a type of flavonoid, found in a variety of plants and plant-derived foods.

${ }^{\mathrm{e}}$ Unclear whether a drug or a natural ingredient.

${ }_{\mathrm{f}}^{\mathrm{f}}$ Naturally occurring organic compound that is used primarily as a flavor enhancer.

${ }^{\mathrm{g}}$ Stimulant.

potential, less than four is advised as a "no-go" or poor relative safety potential. Overall, 11 of the 12 products are a definite no-go according to these criteria.

Are there less than six ingredients on the Supplement Facts label? The number of ingredients on these labels ranged from 8 to 40 total ingredients listed for a product, with an average of 15 ingredients per product. No product reported less than six ingredients on the Supplement Facts label.
Is the Supplement Facts label free of the words proprietary, blend, matrix, or complex? Seven products (58\%) contained and reported proprietary blends, with one including up to 19 named ingredients.

Is there a third-party certification seal on the product bottle? Trusted, gold standard, third-party certifications can be sought through the NSF International, U.S. Pharmacopeia, Banned Substances Control Group, Informed Sport, and other emerging entities. These groups are supposed to 
Table 2. Dietary Supplements Screened According to Operation Supplement SAFETy Scorecard FOr Relative SAFETy

\begin{tabular}{|c|c|c|c|c|c|c|c|c|}
\hline Code no. & $\begin{array}{l}\text { Third-party } \\
\text { certificate }\end{array}$ & $\begin{array}{c}<6 \\
\text { ingredients }\end{array}$ & $\begin{array}{l}\text { Free of words } \\
\text { proprietary, } \\
\text { blend, matrix, } \\
\text { or complex }\end{array}$ & $\begin{array}{c}\text { Easily } \\
\text { pronounce } \\
\text { names } \\
\text { of ingredients }\end{array}$ & $\begin{array}{l}\text { Caffeine } \\
\text { limited to } \\
\leq 200 \mathrm{mg}\end{array}$ & $\begin{array}{c}\text { Free of } \\
\text { "questionable" } \\
\text { claims }\end{array}$ & $\begin{array}{l}\text { \% Daily } \\
\text { values } \\
<200 \%\end{array}$ & $\begin{array}{l}\text { Go or } \\
\text { no-go }\end{array}$ \\
\hline NCNPR394PR & 0 & 0 & 0 & - & 1 & 0 & 0 & No go \\
\hline NCNPR395PR & 0 & 0 & 1 & - & 1 & 0 & $0-\mathrm{NE}$ & No go \\
\hline NCNPR408PR & 0 & 0 & 1 & - & 1 & 0 & $0-\mathrm{NE}$ & No go \\
\hline NCNPR398PR & 0 & 0 & 1 & - & 1 & 0 & 0 & No go \\
\hline NCNPR397PR & 0 & 0 & 0 & - & 1 & 0 & 0 & No go \\
\hline NCNPR393PR & 0 & 0 & 0 & - & 1 & 0 & 0 & No go \\
\hline NCNPR412PR & 0 & 0 & 0 & - & 1 & 0 & 0 & No go \\
\hline NCNPR392PR & 0 & 0 & 0 & - & 1 & 0 & 0 & No go \\
\hline NCNPR399PR & 1 & 0 & 0 & - & 1 & 0 & 0 & No go \\
\hline NCNPR406PR & 0 & 0 & 0 & - & 1 & 0 & 0 & No go \\
\hline NCNPR396PR & 0 & 0 & 1 & - & 1 & 0 & $0-\mathrm{NE}$ & No go \\
\hline NCNPR469PR & 0 & 0 & 1 & - & 1 & 1 & $0-\mathrm{NE}$ & Borderline \\
\hline
\end{tabular}

NE, not established for all ingredients listed on Supplement Facts label. Yes $=1$, no $=0$.

verify that the quality of the products and ingredients meets expectations and to ensure that the products are not contaminated with drugs or other agents that could lead to health concerns or positive drug tests. Manufacturers that have undergone this verification process are able to insert a seal on their product label to ensure public safety for the product they advertise. However, much variability exists among such organizations. Recently, Eichner et al. published a consensus article defining what the gold standard should be for such certifications, but very few, if any, meet those standards. ${ }^{25}$ Importantly, only 1 of the $12(8 \%)$ products contained a thirdparty certification on its product label (BCGS). It is important to note that through qualitative analysis, this product label matched what was detected through analysis.

Is the amount of caffeine limited on the label $200 \mathrm{mg}$ or less per serving? (if caffeine is not listed, mark "yes"). None of the products reported containing more than $200 \mathrm{mg}$ of caffeine on any label.

Are all the \% daily values on the Supplement Facts label less than 200\%? (if \% daily values are not listed, mark "no"). Eight of the 12 products contained an ingredient that was over $200 \%$ for $\%$ daily values (\% DV), with the largest reported DV at $10,416 \%$. Four of the 12 products either did not report \% DV for each of the ingredients or reported it as "not established" for select ingredients.

Can you easily pronounce the name of each ingredient on the Supplement Facts label? A consumer's inability to pronounce an ingredient is usually a good indication that the ingredient is foreign to them. Although this is an important criterion to assess, it is not commented on here due to its subjective nature.

Is the label free of questionable claims or statements? Claims on product bottles consisted of statements, such as "boost the function of your brain and memory," "memory booster to help you retain information and recall it with greater ease," "..uncover your true mental potent," "elevate your mental performance," and "igniting acute mental focus and fueling endurance." Only one product was considered to be free of such "questionable" claims or statements. Costs ranged from $\sim \$ 14.79$ for 30 capsules to as much as $\$ 121.00$ for 60 tablets.

\section{Scientific-sounding claims}

Ninety-two percent (11/12) of products had scientificsounding claims, reported either on the product bottles or the manufacturer websites advertising the product. Examples of these scientific-sounding claims were worded as "clinically proven," "contains only ingredients that have been validated by clinical studies," "proven to provide brain function support," "formulation built off of real science" "best, most scientifically researched ingredients," and "research suggests it works the first time you take it."

Of these reported claims, $55 \%(6 / 11)$ referred to individual ingredients contained in their product and $18 \%(2 / 11)$ referred to the specific formulation of the product. It was unclear whether claims on the remaining three products referred to the product or select ingredients. None of the visited manufacturer websites cited published work on their specific products. Of the two that referred to research on their product claims, one of the manufacturer's websites did have a downloadable report of the clinical research; however, it did not appear to have been published, and so, whether it has undergone any external peer-review process is unknown. The second product website did not contain actual reference citations to published work but alluded to some work as published.

The authors searched PubMed and ran Google searches in an attempt to identify clinical trials across all select 12 named products that may not have been reported by the manufacturers; clinical trials, some sponsored by industry and others with contradictory results, were only found for one product. Although peer-reviewed literature on ingredients commonly listed in these 12 products is available, it is questionable whether this literature has been validated for the specific claims made and the dose and administration presented, or in combination with the other ingredients listed on the Supplement Facts labels of these products, to understand relative safety and/or efficacy/effectiveness. 
Seven $(58 \%)$ products had general warnings on their labels, such as not to use more than the recommended dose, to consult a physician before use if taking other medications, not for use in pregnant or nursing women or children; only two (16\%) product labels contained specific warnings as per an ingredient; one warning not to exceed the use of recommended dose due to caffeine in the product and the other a warning that St. John's wort may cause skin irritation in persons exposed to sunlight.

\section{Discussion}

The dietary supplement market for promoting brain health and cognitive performance is growing as a multibillion dollar business as it targets not only the aging concerned with or experiencing cognitive decline but also healthy adults seeking to improve or enhance performance or prevent a decline. The purpose of this project was to identify dietary supplement products and the ingredients contained in products marketed for brain health and cognitive performance and perform both qualitative analyses with respect to label claims and declared ingredients across select products.

Of the 12 selected products, analyses showed the 8 had ingredients listed on the product label not detected through analysis and 10 products had ingredients detected that were missing from the product label. These products should therefore be considered "adulterated" and "misbranded"; the manufacturers are required to label their products according to the specific labeling requirements put forward in the 25-yearold DSHEA and current FDA regulations. ${ }^{26}$ Only one product was found to contain what was reported on the Supplement Facts label and was third-party certified. The claims made on labels and through advertisement could be deceiving the consumer and are not backed by science for effectiveness or perhaps more importantly, the safety of the ingredients in the unique formulations is not established, at least according to peer-reviewed publications. The authors are waiting to see how the FDA plans to "modernize" DSHEA and other regulations surrounding dietary supplements.

In a separate effort, the authors are using systematic review methods to evaluate the available data for otherwise healthy adults across these frequently used ingredients. Although it is important these systematic tools be used in making decisions for the public's health, the authors unfortunately know that scientific data are often not the reason individuals are drawn to dietary supplement products. In fact, Harvard School of Public Health researchers surveyed supplement users in 2001 , and $72 \%$ reported they would continue using supplements despite a negative government study. ${ }^{27}$ The majority of U.S. adults $(87 \%)$ have overall confidence in the safety, quality, and effectiveness of dietary supplements and $78 \%$ of the Americans perceive the dietary supplement industry as "trustworthy.", Most individuals report getting information about supplements from family, friends, advertisements, and the Internet. Because the public is under the impression that these products are "natural" then they therefore must be safe, but this is not necessarily accurate, especially when many products are adulterated and misbranded.

The goal of this article is to educate the public and raise consumer awareness of what factors to consider when purchasing or recommending the use of brain health dietary supplement products. The authors offer the Operation Supplement
Safety (OPSS.org) scorecard as a quick and easy tool for screening and looking for potential red flags on product labels. This scorecard was developed for the Department of Defense and has proven useful as an educational tool with SM; it can serve as a tool for anyone interested in dietary supplements. As the dietary supplement market continues to grow exponentially, it is important for the public to be aware of deceiving claims, the quality, safety, and the labeling of these products that may be misbranded and could put the health of the public at risk.

\section{Limitations}

The authors selected products queried by SM, a population commonly targeted by the market for products to enhance cognitive performance. The authors do not know if these products could be unique to the military population or if these products are representative of the most popular products on the market. While 650 products were identified and the ingredients contained in those products catalogued for this effort, no market analysis was conducted to determine the most prevalent products on the market targeting the general public. In addition, while they confirmed the contents as either present or absent from the product through analysis, no quantitative analysis was performed to determine whether the amount declared on the labels matched the analysis.

\section{Practice implications}

The results of this study raise a number of significant public health concerns. Among only 12 of 650 products marketed for brain health, $83.3 \%(10 / 12)$ of the products contained ingredients not listed on the label with an average of 3.3 unlisted ingredients. In addition, $67 \%$ (8 of 12) of the products had ingredients listed on the label that were not detected: $\sim 18 \%$ of the total number of ingredients listed were not found in the product. The average number of ingredients in the products overall ( $\sim 12$ : range $6-24)$ begs the question of why do manufacturers believe that more ingredients make a product more enticing, when in fact the risk of problems increases given the greater number of possible interactions. Another concern is the finding that only 2 of the 12 products had labels consistent with the analyses. Importantly-one of those had been certified/verified by a third-party organization. How can we effectively communicate this message to the public at large and encourage them to demand third-party certification, which ensures a level of quality? The potential public health consequences of unknown interactions due to multiple combinations of ingredients, questionable claims and statements on labels and in marketing materials, poor quality assurance, and gaps in knowledge about safety and efficacy need to be addressed to protect the public.

\section{Conclusion}

This study identified 650 dietary supplement products being marketed for brain health and cognitive performance and the frequently used ingredients found in products. Of 12 selected products, content analysis showed that the majority of products had at least one ingredient listed on the label not detected through analysis or compounds detected not reported on the label. Many scientific claims made by manufacturers through advertisements are not supported by the published scientific literature in terms of efficacy or safety. 
Educating the public as to potential red flags when considering the purchase of dietary supplements is imperative while we await the "modernization of the 25-year-old DSHEA.

\section{Acknowledgment}

The authors acknowledge Ms. Andrea T. Lindsey, Director of Operation Supplement Safety (OPSS.org), for her contributions.

\section{Disclaimer}

The opinions and assertions expressed herein are those of the author(s) and do not necessarily reflect the official policy or position of the Uniformed Services University, U.S. Special Operations Command, or the Department of Defense. The contents of this publication are the sole responsibility of the author(s) and do not necessarily reflect the views, opinions, or policies of The Henry M. Jackson Foundation for the Advancement of Military Medicine. The authors have no financial interests or relationships to disclose.

\section{Authors' Contributions}

P.A.D., C.C., B.A., Y.W., and I.A.K. designed the research; C.C., C.B., B.A., and Y.W. conducted the research; C.C., B.A., C.B., P.A.D., and Y.W. analyzed the data; C.C., C.B., B.A., P.A.D., I.A.K., and Y.W. wrote and edited the article; and C.C. and P.A.D. had the primary responsibility for the final content. All authors read and approved the final article.

\section{Author Disclosure Statement}

No competing financial interests exist.

\section{Funding Information}

Funding for this work was provided by the Preservation of the Force and Family Behavioral Health Program, Uniformed Services University award number HU0001-15-2-0053, and the Consortium for Health and Military Performance.

\section{Supplementary Material}

Supplementary Data S1

Supplementary Data S2

Supplementary Data S3

\section{References}

1. Global Council on Brain Health [homepage on the Internet]. The real deal on brain health supplements: GCBH recommendations on vitamins, minerals, and other dietary supplements. Online document at: www.GlobalCouncilOnBrainHealth.org DOI: https://doi.org/10.26419/pia.00094.001.2019, accessed September 20, 2019.

2. Council for Responsible Nutrition [homepage on the Internet]. Consumer survey on dietary supplements. Online document at: https://www.crnusa.org/CRNConsumerSurvey2018, accessed September 20, 2019.

3. Knapik JJ, Trone DW, Austin KG, et al. Prevalence, adverse events, and factors associated with dietary supplement and nutritional supplement use by US Navy and
Marine Corps Personnel. J Acad Nutr Diet 2016;116:14231442.

4. Knapik JJ, Steelman RA, Hoedebecke SS, et al. A systematic review and meta-analysis on the prevalence of dietary supplement use by military personnel. BMC Complement Altern Med 2014;14:143.

5. Binns CW, Lee MK, Lee AH. Problems and prospects: Public health regulation of dietary supplements. Annu Rev Public Health 2018;39:403-420.

6. Starr RR. Too little, too late: Ineffective regulation of dietary supplements in the United States. Am J Public Health 2015; 105:478-485.

7. FDA takes action against 17 companies for illegally selling products claiming to treat Alzheimer's disease [press release] [homepage on the Internet]. 2019. Online document at: https://www.fda.gov/NewsEvents/Newsroom/ PressAnnouncements/ucm631064.htm, accessed September 20, 2019.

8. Attipoe S, Cohen PA, Eichner A, Deuster PA. Variability of stimulant levels in nine sports supplements over a 9-month period. Int J Sport Nutr Exerc Metab 2016;26:413-420.

9. Attipoe S, Leggit J, Deuster PA. Caffeine content in popular energy drinks and energy shots. Mil Med 2016;181: 1016-1020.

10. Avula B, Chittiboyina AG, Bae JY, et al. The power of hyphenated chromatography-time of flight mass spectrometry for unequivocal identification of spirostanes in bodybuilding dietary supplements. J Pharm Biomed Anal 2019; 167:74-82.

11. Cohen PA. The FDA and adulterated supplementsdereliction of duty. JAMA Netw Open 2018;1:e183329.

12. Cohen PA, Wen A, Gerona R. Prohibited stimulants in dietary supplements after enforcement action by the US Food and Drug Administration. JAMA Intern Med 2018;178: 1721-1723.

13. Tucker J, Fischer T, Upjohn L, et al. Unapproved pharmaceutical ingredients included in dietary supplements associated with US Food and Drug Administration warnings. JAMA Netw Open 2018;1:e183337.

14. Operation Supplement Safety [homepage on the Internet]. Screen your supplement for safety. Online document at: https://www.opss.org/screen-your-supplement-safety-readlabel-your-supplement-and-answer-these-questions, accessed September 20, 2019.

15. Attipoe S, Manganello C, Scott JM, Deuster PA. Usefulness of a risk assessment tool to risk stratify dietary supplements. Mil Med 2017;182:e2086-e2091.

16. Baker B. Military effectiveness of five dietary supplements purported to aid cognitive and physical performance. J Mil Veterans Health 2017;25:35-47.

17. Butler M, Nelson VA, Davila H, et al. Over-the-counter supplement interventions to prevent cognitive decline, mild cognitive impairment, and clinical alzheimer-type dementia: A systematic review. Ann Intern Med 2018; 168:52-62.

18. D'Cunha NM, Georgousopoulou EN, Dadigamuwage L, et al. Effect of long-term nutraceutical and dietary supplement use on cognition in the elderly: A 10-year systematic review of randomised controlled trials. Br J Nutr 2018;119:280-298.

19. Ford AH, Almeida OP. Effect of Vitamin B supplementation on cognitive function in the elderly: A systematic review and meta-analysis. Drugs Aging 2019;36:419-434. 
20. McCleery J, Abraham RP, Denton DA, et al. Vitamin and mineral supplementation for preventing dementia or delaying cognitive decline in people with mild cognitive impairment. Cochrane Database Syst Rev 2018;11:Cd011905.

21. McGrattan AM, McEvoy CT, McGuinness B, et al. Effect of dietary interventions in mild cognitive impairment: A systematic review. Br J Nutr 2018;120:1388-1405.

22. Rutjes AW, Denton DA, Di Nisio M, et al. Vitamin and mineral supplementation for maintaining cognitive function in cognitively healthy people in mid and late life. Cochrane Database Syst Rev 2018;12:Cd011906.

23. Kazlauskas R. Advances in sports drug testing: An overview. Drug Test Anal 2010;2:523-525.

24. FDA Statement [homepage on the Internet]. Statement on warning for women of childbearing age about possible safety risks of dietary supplements containing vinpocetine. 2019. Online document at: https://www.fda.gov/news-events/ press-announcements/statement-warning-women-childbearingage-about-possible-safety-risks-dietary-supplements-contain ing, accessed January 5, 2020.

25. Eichner AK, Coyles J, Fedoruk M, et al. Essential features of third-party certification programs for dietary supple- ments: A consensus statement. Curr Sports Med Rep 2019; $18: 178-182$.

26. US Food and Drug Administration [homepage on the Internet]. Dietary Supplement Labeling Guide. 2005. Online document at: https://www.fda.gov/food/dietary-supplementsguidance-documents-regulatory-information/dietary-supple ment-labeling-guide, accessed September 20, 2019.

27. Blendon RJ, DesRoches CM, Benson JM, et al. Americans' views on the use and regulation of dietary supplements. Arch Intern Med 2001;161:805-810.

Address correspondence to:

Cindy Crawford, BA

Consortium for Health and Military Performance Department of Military and Emergency Medicine

F. Edward Hébert School of Medicine Uniformed Services University 4301 Jones Bridge Road Bethesda, MD 20814

E-mail: cindy.crawford.ctr@usuhs.edu 